PANCREAS AND BILIARY TRACT

\title{
Are we meeting the standards set for endoscopy? Results of a large-scale prospective survey of endoscopic retrograde cholangio-pancreatograph practice
}

\author{
Earl J Williams, Steve Taylor, Peter Fairclough, Adrian Hamlyn, Richard F Logan, Derrick Martin, \\ Stuart A Riley, Peter Veitch, Mark Wilkinson, Paula R Williamson, Martin Lombard on behalf of \\ participating units, BSG Audit of ERCP
}

Gut 2007;56:821-829. doi: 10.1136/gut.2006.097543

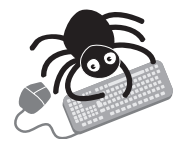

Six supplemental files are available at http://gut.bmi. com supplemental.

See end of article for authors' affiliations

......................

Correspondence to: Dr M Lombard, Audit Steering Group, Department of Gastroenterology, $5 z$ Link, Royal Liverpool University Hospital, Prescot St, Liverpool L7 8XP, UK; martin.lombard@

rlbuht.nhs.uk

Revised 20 September 2006 Accepted 17 October 2006 Published Online First 1 December 2006
Objective: To examine endoscopic retrograde cholangio-pancreatography (ERCP) services and training in the UK.

Design: Prospective multicentre survey.

Setting: Five regions of England.

Participants: Hospitals with an ERCP unit.

Outcome measures: Adherence to published guidelines, technical success rates, complications and mortality. Results: Organisation questionnaires were returned by 76 of $81(94 \%)$ units. Personal questionnaires were returned by 190 of $213(89 \%)$ ERCP endoscopists and 74 of 91 (81\%) ERCP trainees, of whom $45(61 \%)$ reported participation in $<50$ ERCPs per annum. In all, 66 of $81(81 \%)$ units collected prospective data on 5264 ERCPs, over a mean period of 195 days. Oximetry was used by all units, blood pressure monitoring by 47 of $66(71 \%)$ and ECG monitoring by 37 of $66(56 \%)$ units; 1484 of $4521(33 \%)$ patients were given $>5 \mathrm{mg}$ of midalozam. Prothrombin time was recorded in 4539 of $5264(86 \%)$ procedures. Antibiotics were given in 1021 of $1412(72 \%)$ cases, where indicated. Patients' American Society of Anesthesiology (ASA) scores were 3-5 in 670 of 5264 (12.7\%) ERCPs, and 4932 of 5264 (94\%) ERCPs were scheduled with therapeutic intent. In total, 140 of $182(77 \%)$ trained endoscopists demonstrated a cannulation rate $\geqslant 80 \%$. The recorded cannulation rate among senior trainees (with an experience of $>200$ ERCPs) was 222/338 (66\%). Completion of intended treatment was done in 3707 of 5264 (70.4\%) ERCPs; 268 of 5264 (5.1\%) procedures resulted in a complication. Procedure-related mortality was $21 / 5264(0.4 \%)$. Mortality correlated with ASA score.

Conclusion: Most ERCPs in the UK are performed on low-risk patients with therapeutic intent. Complication rates compare favourably with those reported internationally. However, quality suffers because there are too many trainees in too many low-volume ERCP centres.
- ndoscopic retrograde cholangio-pancreatography (ERCP)

E is an important tool in the diagnosis and treatment of pancreatobiliary disease. However, it has been associated with an incidence of complication ranging from $4 \%$ to $30 \% .^{1}$ In 2004, the UK's National Confidential Enquiry into Patient Outcome and Death (NCEPOD) published an analysis of deaths after therapeutic endoscopy. ${ }^{2}$ Findings suggested that ERCP services were deficient in a number of areas. Of particular concern was the number of patients subjected to an ERCP that was considered futile or inappropriate (table 1). This is an important issue, as poor patient selection is likely to be associated with a greater number of adverse events. ${ }^{3-6}$ The aim of this paper is to examine the quality of current ERCP training and practice, using data from the British Society of Gastroenterology (BSG) audit of ERCP.

\section{METHODS}

In 2004, the BSG audit of ERCP availability, quality and outcomes surveyed ERCP practice across five metropolitan regions of England: the North West, the West Midlands, Trent, North Thames and South Thames. Approval was secured from a multicentre research ethics committee, relevant local research ethics committees, and the research and development department of each institution.

Within the five regions, 81 hospitals provided an adult ERCP service. A total of 213 ERCP endoscopists worked within these units, and were involved in training 91 specialist registrars. The study entailed:

1. Completion of one questionnaire, relating to unit organisation, by a senior endoscopist.

2. Completion of a questionnaire, relating to training, experience and usual practice, by each ERCP endoscopist and each ERCP trainee.

3. A period of prospective data collection, during which participating endoscopists completed a procedure questionnaire for each consecutive ERCP. To comply with ethics committee requirements, patient consent for data transfer and follow-up was sought. ERCP was defined as any endoscopic procedure carried out with an intention to cannulate the common bile duct and/or pancreatic duct. Patients under the age of 18 years were excluded. A designated liaison officer within each unit made contact with the patient or his or her carer 1 day after ERCP. A second check on outcome was made a minimum of 30 days after the procedure. Information for the latter was sought from the patient and his or her family, or at least from the

\footnotetext{
Abbreviations: ASA, American Society of Anesthesiology; BSG, British Society of Gastroenterology; ERCP, endoscopic retrograde cholangiopancreatography; NCEPOD, National Confidential Enquiry into Patient Outcome and Death
} 
Table 1 Summary of the National Confidential Enquiry into Patient Outcome and Death recommendations relevant to endoscopic retrograde cholangio-pancreatography

\begin{tabular}{|c|c|c|}
\hline Area of practice & NCEPOD findings* & NCEPOD recommendations \\
\hline Unit organisation & $\begin{array}{l}6 \% \text { of units had no dedicated recovery area } \\
19 \% \text { of units had no resuscitation facilities in the department }\end{array}$ & $\begin{array}{l}\text { Monitoring and resuscitation equipment in each } \\
\text { endoscopy room and recovery area } \\
\text { Units to consider establishing formal on-call } \\
\text { arrangements }\end{array}$ \\
\hline Consent practice & $\begin{array}{l}\text { No written consent was obtained for } 21 \% \text { of patients who } \\
\text { died; } 16 \% \text { of deaths in patients with acute confusion or } \\
\text { dementia, but written consent still obtained for } 2 / 3 \text { of these }\end{array}$ & $\begin{array}{l}\text { The risks and benefits of therapeutic endoscopy should } \\
\text { be explained to the patient } \\
\text { The ability of those with dementia or acute confusion to } \\
\text { provide consent should be tested }\end{array}$ \\
\hline Patient preparation & $\begin{array}{l}87 \% \text { of ERCPs reviewed had received antibiotics } \\
\text { In } 80 \% \text { of ERCPs reviewed, no record of clotting tests }\end{array}$ & $\begin{array}{l}\text { Antibiotic prophylaxis should be used as per BSG } \\
\text { guidelines } \\
\text { Bilirubin and clotting results available before ERCP }\end{array}$ \\
\hline Sedation and monitoring & $\begin{array}{l}23 \% \text { of cases inadequately monitored; } \\
3 \% \text { of procedures monitored by the endoscopist alone; } \\
14 \% \text { of cases inappropriately (excessively) sedated }\end{array}$ & $\begin{array}{l}\text { Formal training and assessment with audit and review } \\
\text { of practice } \\
\text { National guidelines on monitoring recommended } \\
\text { Unit protocol for the administration of sedation }\end{array}$ \\
\hline Training and education & $\begin{array}{l}11 \% \text { of deaths were related to ERCPs performed by an } \\
\text { endoscopist performing }<50 \text { ERCPs per annum } \\
42 \% \text { of units not conducting audit } \\
97 \% \text { of ERCP cases were performed by a consultant }\end{array}$ & $\begin{array}{l}\text { National guidelines for assuring continuing competency } \\
\text { recommended } \\
\text { All units to audit deaths within } 30 \text { days of ERCP } \\
\text { Experience should be appropriate to the procedure }\end{array}$ \\
\hline Patient selection, assessment and outcome & $\begin{array}{l}77 \% \text { of deaths following ERCP were among those with } \\
\text { ASA grade } 3-5 ; \\
1 / 3 \text { of urgent ERCPs resulting in death were considered } \\
\text { appropriate; } \\
68 \% \text { of ERCPs performed were considered futile } \\
\text { Critical incidents at the time of endoscopy } \geqslant 9 \% \\
\text { Progression of disease and sepsis were the most common } \\
\text { contributors to death }\end{array}$ & $\begin{array}{l}\text { Patients should be reviewed by the consultant } \\
\text { endoscopist before therapeutic ERCP to ensure that the } \\
\text { procedure is appropriate and patient optimised }\end{array}$ \\
\hline
\end{tabular}

hospital's computer records. Patients could also report adverse events directly to EJW. The patients' supervising clinicians were informed in writing of their participation. Where a delayed discharge or unplanned readmission was identified, the patient's case notes were reviewed to establish the type and severity of the adverse event.

Data from local centres were manually checked by the chief investigator and entered onto a central database using an

Table 2 Summary of patients not consenting to participate in the study

\begin{tabular}{lcc}
\hline & $\begin{array}{l}\text { Number of } \\
\text { ERCPs }\end{array}$ & $\begin{array}{l}\text { Percentage of } \\
\text { consecutive ERCPs } \\
\text { during study } \\
\text { period } \\
\text { (n=6910) }\end{array}$ \\
$\begin{array}{l}\text { Reason for consent } \\
\text { not being obtained }\end{array}$ & 323 & 4.7 \\
\hline $\begin{array}{l}\text { Non-participating endoscopist } \\
\text { Patient declined }\end{array}$ & 265 & 3.8 \\
$\begin{array}{l}\text { Insufficient time to obtain consent } \\
\text { rrom the patient }\end{array}$ & 734 & 10.6 \\
$\begin{array}{l}\text { Chronic cognitive impairment } \\
\text { precluded informed consent }\end{array}$ & 92 & 1.3 \\
$\begin{array}{l}\text { Patient too sick to consent } \\
\text { Non-English speaker-translator }\end{array}$ & 98 & 1.4 \\
not available & 28 & 0.4 \\
$\begin{array}{l}\text { Sensory impairment (eg, deafness) } \\
\text { precluded consent } \\
\text { Unknown }\end{array}$ & 18 & 0.3 \\
\begin{tabular}{l} 
Total \\
\hline
\end{tabular} & 88 & 1.3 \\
\hline
\end{tabular}

ERCP, endoscopic retrograde cholangio-pancreatography. optical scanner with integrated data-capture and validation software (Cardiff Teleform V.8).

\section{RESULTS}

Questionnaires on unit organisation and facilities were received from 76 of 81 (94\%) units. Questionnaires detailing experience and usual practice were received from 190 of 213 (89\%) ERCP endoscopists and 74 of 91 (81\%) ERCP trainees. During a mean (SD) study period of 195 days (range $28-310), 182$ of $213(85 \%)$ eligible endoscopists and 66 of $81 \quad(81 \%)$ eligible units participated in prospective data collection. The date of commencement for each unit depended on receipt of local ethics approval and identification of a suitable liaison officer. Inclusion of patients ceased at the end of 2004.

Patient consent to data transfer and follow-up was obtained for 5264 ERCPs. This represented $76 \%$ of the 6910 consecutive ERCPs undertaken by participating units during the study period, and $80 \%$ of the procedures performed by participating endoscopists (table 2).

A total of 5088 of 5264 (97\%) procedures analysed were followed up for a minimum of $24 \mathrm{~h}$, and 4817 of 5264 (92\%) for 30 days. Questionnaires on satisfaction were received from 2059 of 4561 (45\%) patients who participated.

Extrapolating from prospective returns (and taking into account patients not entered into the study), an average unit was found to perform just over 200 procedures per annum. This implies that around 48000 procedures were performed by the UK's 236 acute hospitals in 2004. It also suggests that the 5264 procedures analysed represented about $20 \%$ of the total number of procedures performed nationally during the (mean) study period of 6 months. 
Table 3 Summary of unit staffing and facilities

\begin{tabular}{lc}
\hline Facilities and staff & $\begin{array}{c}\text { Percentage of units } \\
\text { with the facility (n) }\end{array}$ \\
\hline $\begin{array}{l}\text { Recovery area within or adjacent to where ERCP } \\
\text { was performed }\end{array}$ & $72(55)$ \\
Appropriately stocked resuscitation trolley & $87(66)$ \\
Within the department & $16(12)$ \\
Within the ERCP room & $84(64)$ \\
EUS or MR cholangiography available on-site & $12(9)$ \\
ERCP services provided by a single consultant & $100(76)$ \\
Surgeon with an interest in upper gastrointestinal & \\
surgery on-site & $88(67)$ \\
Radiologist with an interest in upper gastrointestinal & \\
disease on-site & $78(59)$ \\
MDT meetings to discuss hepatobiliary cases & $61(46)$ \\
Weekly MDT meeting & \\
\hline ERCP, endoscopic retrograde cholangio-pancreatography; EUS, \\
endoscopic ultrasound; MDT, multidisciplinary team; MR, magnetic \\
resonance.
\end{tabular}

\section{Organisation of units}

Of the 76 hospitals that returned the unit questionnaire, 42 (55\%) provided an ERCP service for their local population only; $24(32 \%)$ received referrals from other hospitals in their region and $10(13 \%)$ received referrals from hospitals outside their region. Consistent with this, 49 of 76 (64\%) ERCP units described themselves as a district general (as opposed to university) hospital. In the year before the audit, the median number of ERCPs performed per unit was 235 (range 58-820, with the exception of one unit where ERCP services commenced in 2004). Overall, $45 \%$ of units performed between 100-200 procedures per year. Of the 190 respondents to the endoscopist questionnaire, 149 (78\%) were medical gastroenterologists. Table 3 summarises the other aspects of unit organisation.

\section{Training and education}

During the audit period, 51 of $81(63 \%)$ units provided ERCP training for 91 trainees (specialist registrars). Of these units, 26 $(51 \%)$ were district general hospitals. For units engaged in training, a minimum workload of 250 procedures per annum has been recommended. ${ }^{7}$ On the basis of responses to the unit questionnaire, 25 of 51 (49\%) training units participating in this study were found to have met or exceeded this requirement.

Of the 91 specialist registrar trainees identified, 74 (81\%) supplied information about their experiences. Respondents had been in grade for an average of 4.1 years (range $0-8$ ). Nearly all respondents were gastroenterology trainees, with only three radiology trainees and one surgical trainee. With regard to training received in diagnostic upper endoscopy, 60 of $74(81 \%)$ trainees had participated in $>200$ gastroscopies before their first ERCP. This suggested that most had achieved competency in basic upper gastrointestinal endoscopy. Regardless of the stage of training, the majority $(45 / 74(61 \%))$ of ERCP trainees had participated in $<50$ supervised ERCPs in the preceding year. This contrasted with the number of procedures performed per annum by the 177 consultants, of whom only 27 (15\%) were performing $<50$ ERCPs per annum.

It has been suggested that an average trainee needs to participate in a total of 180-200 ERCPs to attain competence. ${ }^{8}$ Of the 37 respondents in year 5 or above of training, $14(38 \%)$ reported performing $>200$ supervised ERCPs before the commencement of audit. During prospective data collection, this group attempted cannulation in 338 ERCPs, and were recorded as successful without physical assistance in $222(66 \%)$ procedures. In the remaining procedures, the trainee was

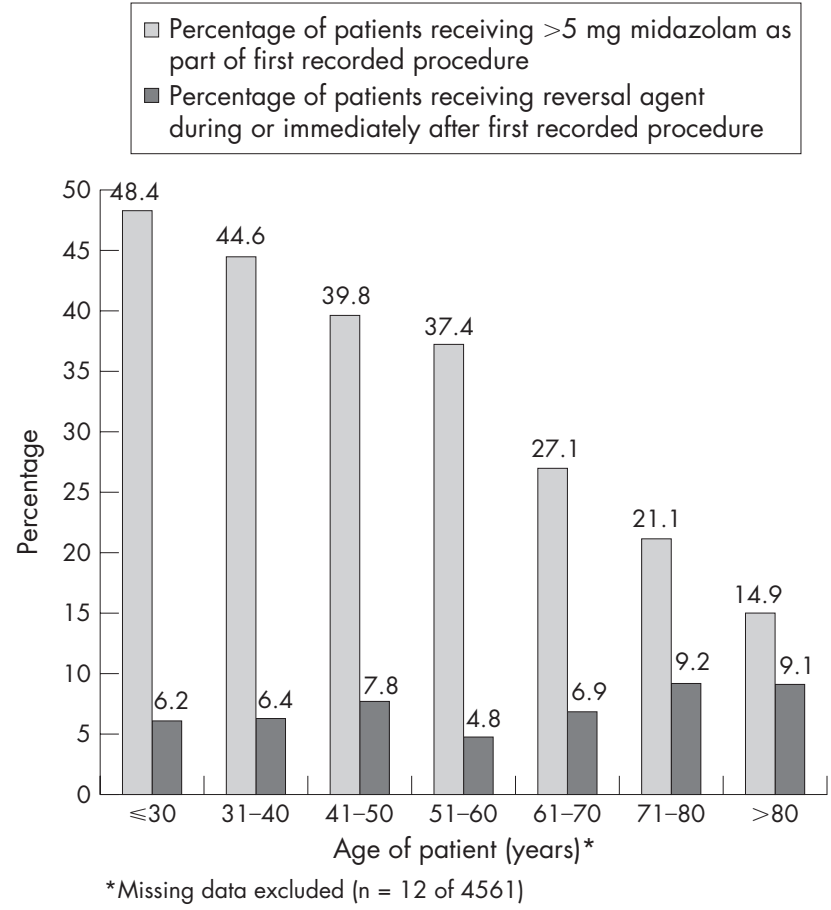

Figure 1 Use of sedation and reversal agents according to age.

recorded as unsuccessful, or there was no comment made on the trainee's contribution. Excluding procedures where a contribution by the trainee was not recorded, the cannulation rate was at most 222/298 (74\%). These results contrast with the 23 of $37(62 \%)$ trainees in year 5 or above of training who reported performing $<200$ supervised procedures before the audit commenced. During prospective data collection, this group attempted cannulation in 368 ERCPs, and were recorded as successful without physical assistance in 140 (38\%) of procedures. Excluding procedures where a contribution by the trainee was not recorded, the cannulation rate was at most 140/ $261(54 \%)$. Close supervision of trainees was the norm, with a trained endoscopist being present during 5121 of 5264 (97\%) procedures. Although 56 of $74(76 \%)$ ERCP trainees believed such training to be necessary for career development, only 30 (54\%) of these had a definite intent to perform ERCP as a consultant.

Among trained ERCP endoscopists, ongoing clinical audit was not well established, with only 40 of $190(21 \%)$ reporting that their unit maintained an electronic database of adverse outcomes.

\section{Patient selection and assessment}

In all, 4932 of 5264 (94\%) prospectively studied ERCPs were scheduled with an intention to perform treatment. Intended interventions are discussed further under Completion of ERCP. Urgent procedures accounted for 450 of 5264 (8.5\%) ERCPs, with 214 of $450(48 \%)$ such procedures being performed because of biliary sepsis, acute pancreatitis or biliary leak. Only 670 of $5264(12.7 \%)$ procedures recorded were performed on patients with severe systemic disease, as defined by an American Society of Anesthesiology (ASA) score of 3-5 at the time of ERCP (http://www.asahq.org/clinical/physicalstatus. htm).

In all, 3210 of 4561 patients underwent their first ever ERCP as part of the prospective study. Some form of diagnostic imaging (usually transabdominal ultrasound) preceded ERCP 
Table 4 Drugs used to achieve sedation (patients receiving general anaesthesia/propofol excluded)

\begin{tabular}{lcc}
\hline Drug & $\begin{array}{l}\mathbf{n}(\%) \text { of ERCPs in which } \\
\text { drug was administered* } \\
(\mathbf{n = 5 1 6 9 )}\end{array}$ & $\begin{array}{l}\text { Mean (SD) total } \\
\text { dose administered }\end{array}$ \\
\hline Midazolam & $4521(87)$ & $5.7(3.2) \mathrm{mg}$ \\
Diazepam & $520(10)$ & $13.5(6.8) \mathrm{mg}$ \\
Pethidine & $3191(62)$ & $50.8(18.9) \mathrm{mg}$ \\
Nalbuphane & $649(13)$ & $8.6(4.3) \mathrm{mg}$ \\
Fentanyl & $1069(21)$ & $90.4(44.9) \mathrm{mcg}$ \\
\hline
\end{tabular}

ERCP, endoscopic retrograde cholangio-pancreatography. *In $132(3 \%)$ cases, use of benzodiazepine was not recorded. In four cases, both midazolam and diazepam were recorded as being administered during the course of a single ERCP. Among procedures performed using benzodiazipine, 4724 of 5039 (94\%) involved coadministration of an opioid.

in $3068(96 \%)$ of these patients. An abnormality in prior imaging was noted in 2887 of 3068 (94\%) patients. Similarly, serum bilirubin level was obtained within a week of first ever ERCP for 2578 of $3210(80 \%)$ patients. An elevated bilirubin $(>17 \mu \mathrm{M} / \mathrm{l})$ level was observed in 1758 of $2578(68 \%)$ patients of this group.

Data derived from the unit and endoscopist questionnaires suggested that while 60 of $76(79 \%)$ units had a formal mechanism for screening ERCP referrals, only 30 of 190 (16\%) ERCP endoscopists personally vetted all patients scheduled for ERCP on their lists.

\section{Consent practice}

Current guidelines ${ }^{9}$ recommend that endoscopists provide written information to individuals undergoing ERCP, and inform patients of (1) therapeutic alternatives; (2) participation of trainees; and (3) substantial associated risks (defined as pancreatitis, cholangitis, perforation and bleeding). Information about consent practice was derived from responses to the endoscopist questionnaire. A total of 169 of 190 (89\%) ERCP endoscopists reported that they provided written information to patients before the procedure. Disclosure of risk varied between respondents. ERCP endoscopists were most likely to report disclosing the risk of bleeding (185/190; 97\%), followed by pancreatitis (183/190; 96\%), perforation (171/190; $90 \%$ ) and cholangitis (117/190; 62\%). In all, 76 of $190(40 \%)$ endoscopists discussed alternatives to ERCP with patients "usually" or "always": patients were "usually" made aware if a trainee or other doctor was participating in the list, although only 46 of $190(24 \%)$ endoscopists made a point of "always" informing their patients of this.

\section{Patient preparation}

A written policy on the management of anticoagulated patients undergoing ERCP was present in 55 of $76(72 \%)$ units that responded to the preliminary questionnaire. Of the 68 of 76 $(89 \%)$ units reporting a written policy for patient preparation, 44 of $68(65 \%)$ routinely administered antibiotics.

During prospective study, prothrombin time, performed within 1 week of the procedure, was documented for 4539 of $5264(86 \%)$ ERCPs. In total, 89 of 5264 (2\%) procedures were carried out on patients within $72 \mathrm{~h}$ of administration of a nonsteroidal anti-inflammatory drug, and 205 of 5264 (4\%) within $72 \mathrm{~h}$ of administration of some form of anti-platelet therapy. A total of 1412 of $5264(27 \%)$ ERCPs analysed involved a patient with complete biliary obstruction, pancreatic pseudocyst or cholangitis. Of these, 1021 of $1412(72 \%)$ received antibiotics at the time of the procedure. A further four procedures involved a patient with a total white cell count of $<1 \times 10^{9} / 1$, of which three patients had received antibiotics before ERCP.

\section{Monitoring}

A total of 179 of 190 (94\%) endoscopists reported that they did not undertake ERCP without having an appropriately qualified assistant to monitor the patient. All endoscopists indicated that they used oximetry routinely, and 143 of 190 (75\%) were familiar with either the BSG $^{10}$ or the Academy of Medical Colleges ${ }^{11}$ guidelines on sedation practice. These guidelines specify that a fall in oxygen saturations to $<90 \%$ should prompt immediate intervention. Most responding endoscopists (171/ 181 ; 94\%) quoted a threshold for intervention of $\geqslant 90 \%$, although individual replies to this question ranged from 82 $98 \%$.

In addition to oximetry, supplementary blood pressure (BP) and/or ECG monitoring is recommended for patients who are at risk of hypotension or cardiac ischaemia. ${ }^{11}$ During prospective

Table 5 Deaths following a cardiorespiratory complication

\begin{tabular}{|c|c|c|c|c|c|c|}
\hline Patient & $\begin{array}{l}\text { Age } \\
\text { (years) }\end{array}$ & $\begin{array}{l}\text { ASA } \\
\text { score }\end{array}$ & Indication & Monitoring & Sedation & Comments \\
\hline 1 & 74 & 2 & CBD stones & $\begin{array}{l}\text { Oximetry } \\
\text { BP monitoring }\end{array}$ & $\begin{array}{l}\text { Midazolam } 8 \mathrm{mg} \\
\text { Pethidine } 50 \mathrm{mg}\end{array}$ & $\begin{array}{l}\text { Cardiac arrest during procedure. } \\
\text { Resuscitation failed. Postmortem } \\
\text { revealed severe coronary artery } \\
\text { disease }\end{array}$ \\
\hline 2 & 75 & 3 & $\begin{array}{l}\text { Jaundice secondary } \\
\text { to hilar mass }\end{array}$ & $\begin{array}{l}\text { Oximetry } \\
\text { BP monitoring } \\
\text { ECG monitoring }\end{array}$ & $\begin{array}{l}\text { Midazolam } 2 \mathrm{mg} \\
\text { Pethidine } 50 \mathrm{mg}\end{array}$ & $\begin{array}{l}\text { Pre-existing chronic obstructive } \\
\text { airways disease with low oxygen } \\
\text { saturations before ERCP. Developed } \\
\text { right basal pneumonia after the } \\
\text { procedure and died } 2 \text { days later }\end{array}$ \\
\hline 3 & 73 & 2 & $\begin{array}{l}\text { CBD stone with } \\
\text { cholangitis }\end{array}$ & Oximetry & $\begin{array}{l}\text { Midazolam and } \\
\text { pethidine; dose } \\
\text { unrecorded }\end{array}$ & $\begin{array}{l}\text { Pre-existing cardiac impairment and } \\
\text { chronic obstructive airways disease. } \\
\text { Deterioration following ERCP with } \\
\text { signs of heart failure. Transferred to } \\
\text { ITU. Died } 27 \text { days after the } \\
\text { procedure }\end{array}$ \\
\hline 4 & 88 & 2 & $\begin{array}{l}\text { Jaundice secondary } \\
\text { to pancreatic cancer }\end{array}$ & Oximetry & $\begin{array}{l}\text { Midazolam } 1.5 \mathrm{mg} \\
\text { Pethidine } 25 \mathrm{mg}\end{array}$ & $\begin{array}{l}\text { Attended as day-case. Became } \\
\text { hypoxic and unresponsive after } \\
\text { sedation and intubation. Procedure } \\
\text { had to be abandoned and patient } \\
\text { admitted. Decision made to palliate. } \\
\text { Died } 12 \text { days later }\end{array}$ \\
\hline
\end{tabular}

ASA, American Society of Anesthesiology; BP, blood pressure; CBD, common bile duct; ECG, electrocardiogram; ERCP,endoscopic retrograde cholangiopancreatography. 
Table 6 Intended and completed post-cannulation procedures

\begin{tabular}{|c|c|c|}
\hline Intervention & $\begin{array}{l}\text { Proportion of procedures analysed } \\
\text { where intervention was } \\
\text { intended* } n / N(\%)\end{array}$ & $\begin{array}{l}\text { Completion rate of intended } \\
\text { intervention } \dagger \mathrm{n} / \mathrm{N}(\%)\end{array}$ \\
\hline Biliary sphincterotomy & $2436 / 5264(46)$ & $2044 / 2436(84)$ \\
\hline Bile duct stone extraction & $2114 / 5264(40)$ & $1318 / 2114(62)$ \\
\hline Biliary stent/drain & $1827 / 5264$ (35) & $1341 / 1827$ (73) \\
\hline Biliary cytology & $366 / 5264(7)$ & $262 / 366(72)$ \\
\hline Biliary dilatation & $105 / 5264(2)$ & $89 / 105(85)$ \\
\hline Pancreatic Rx and manometry & $112 / 5264(2)$ & $85 / 112(76)$ \\
\hline \multicolumn{3}{|c|}{$\begin{array}{l}\text { *The endoscopist listed pre-procedure intent, but could modify this in light of ERCP findings. More than one intervention } \\
\text { could be listed per procedure. } \\
\text { tFor stone extraction, completion was defined as complete duct clearance. For stenting/drainage, completion was } \\
\text { defined as an endoprosthesis that crosses stricture; for sphincterotomy, completion was defined as a papillotomy that } \\
\text { facilitates any further procedure. }\end{array}$} \\
\hline
\end{tabular}

data collection, 47 of 66 (71\%) units used BP monitoring on at least one occasion, and 37 of 66 (56\%) used ECG monitoring. Nonetheless, only 108 of $296(36 \%)$ patients who were $\geqslant 75$ years old and of ASA score 3-5 underwent BP monitoring during their first recorded ERCP, and only 52 of 296 (18\%) of the same group underwent ECG monitoring. This suggests that not all vulnerable patients were optimally monitored, even when there were resources available to do so.

\section{Sedation}

A written protocol for sedation existed in 41 of 76 (54\%) units. Midazolam was the sedative of choice among 177 of 190 (93\%) clinicians responding to the endoscopist questionnaire, with 106 of $190(56 \%)$ indicating pethidine as their favoured opioid. Consensus guidelines have suggested that midazolam dose should only rarely exceed $5 \mathrm{mg} \cdot{ }^{10}$ In total, 38 of 190 (20\%) of those responding to the endoscopist questionnaire indicated using an average dose of midazolam of $>5 \mathrm{mg}$.

During prospective study, 79 of 5264 (1.5\%) ERCPs were performed under general anaesthesia. In an additional 16 cases, the endoscopist indicated use of propofol, but did not describe the level of sedation as equivalent to that of a general anaesthetic. Table 4 summarises the drugs administered during the remaining 5169 procedures. It is notable that 1484 of 4521 (33\%) patients undergoing conscious sedation with midazolam received a dose of 5.5-30 mg. In 1377 (93\%) of these patients it was combined with administration of an opioid. A total of 345 of 4561 (7.6\%) patients required reversal agents (flumazenil or naloxone) during their first recorded procedure, or shortly after the procedure. Despite an inverse relationship between dose of midazolam and age, an increased use of reversal agents was observed in older people (fig 1). Four patients had a cardiorespiratory complication that culminated in death (table 5).

\section{Completion of ERCP}

Individual endoscopists performed a mean of 29 ERCPs (range 1-145) during the period of prospective study. It has been proposed that the minimum acceptable cannulation rate for a trained endoscopist is between $80 \%$ and $90 \% .^{72}$ A deep cannulation rate of $\geqslant 80 \%$ was achieved by 140 of $182(77 \%)$ endoscopists, with a deep cannulation rate of $\geqslant 90 \%$ achieved by 77 of $182(42 \%)$. Overall deep cannulation of the duct(s) of interest was achieved in 2684 of 3210 (83.6\%) patients undergoing their first ever ERCP, and in 4554 of 5264 $(86.5 \%)$ procedures recorded. Pancreatograms were obtained in 1756 of $5264(33 \%)$ procedures, of which $1427(81 \%)$ were unintentional. A "pre-cut" (where biliary access is facilitated by incising the papilla) was performed in $465(8.8 \%)$ of the ERCPs studied. Immediate cannulation of the $\operatorname{duct}(\mathrm{s})$ of interest was achieved in 303 of 465 (65\%) pre-cut ERCPs.

Having considered any additional diagnostic information available as a result of the ERCP, the performing endoscopist decided that no post-cannulation intervention was necessary in $14 \%$ of the procedures. For the remainder of procedures, one or more post-cannulation intervention was intended. For such a procedure to be judged technically successful, the endoscopist had to complete all intended interventions. Completion of stone extraction was defined as total (as opposed to partial) duct clearance. Completion of stenting was defined as insertion of an endoprosthesis that crossed the pathology in question. On the basis of intention to treat (ie, including failed intubations and cannulations), the success rate of particular interventions

Table 7 Definitions of endoscopic retrograde cholangio-pancreatography-related complication ${ }^{13}$

\begin{tabular}{|c|c|c|c|}
\hline Complication & Mild & Moderate & Severe \\
\hline Bleeding & $\begin{array}{l}\text { Clinical (not just endoscopic) } \\
\text { evidence of bleeding; } \mathrm{HB} \text { drop }<3 \mathrm{~g} \text {; } \\
\text { no transfusion }\end{array}$ & $\begin{array}{l}\text { Transfusion (4 } \mathrm{U} \text { or less), no angiographic } \\
\text { or surgical intervention }\end{array}$ & $\begin{array}{l}\text { Transfusion ( } \geqslant 5 \mathrm{U} \text { ) or intervention } \\
\text { (angiographic or surgical), or resulting in death }\end{array}$ \\
\hline Perforation & $\begin{array}{l}\text { Possible or slight leak of contrast; } \\
\text { treated by fluids and suction } \\
\text { for } \leqslant 3 \text { days }\end{array}$ & $\begin{array}{l}\text { Any definite perforation treated medically } \\
\text { for } 4-10 \text { days }\end{array}$ & $\begin{array}{l}\text { Hospitalisation for }>10 \text { days or any } \\
\text { intervention (percutaneous or surgical), or } \\
\text { resulting in death. }\end{array}$ \\
\hline $\begin{array}{l}\text { Pancreatitis (abdominal pain } \\
\text { and amylase }>3 \mathrm{~N} \text { after } 24 \mathrm{~h} \text { ) }\end{array}$ & $\begin{array}{l}\text { Requiring admission or prolongation } \\
\text { of planned admission to } \geqslant 2 \text { nights }\end{array}$ & Requiring 4-10 days of hospitalisation & $\begin{array}{l}\text { Admission for }>10 \text { days; haemorrhagic } \\
\text { pancreatitis; pseudocyst; intervention required; } \\
\text { death }\end{array}$ \\
\hline Infection (cholangitis) & $>38^{\circ} \mathrm{C}$ for $24-48 \mathrm{~h}$ & $\begin{array}{l}\text { Febrile or septic illness requiring }>3 \text { days } \\
\text { hospitalisation or endoscopic/percutaneous } \\
\text { intervention }\end{array}$ & Septic shock or surgery, or resulting in death \\
\hline $\begin{array}{l}\text { Miscellaneous (includes } \\
\text { symptomatic IHD, aspiration } \\
\text { pneumonia, drug reactions) }\end{array}$ & $\begin{array}{l}\text { Onset of relevant symptoms within } \\
3 \text { days of ERCP } \\
\text { Requires } 1-3 \text { days of hospitalisation/ } \\
\text { prolongation of stay }\end{array}$ & $\begin{array}{l}\text { Onset of relevant symptoms within } 3 \text { days of } \\
\text { ERCP, requiring 4-10 days of hospitalisation }\end{array}$ & $\begin{array}{l}\text { Onset of relevant symptom within } 3 \text { days of } \\
\text { ERCP, requiring }>10 \text { days of hospitalisation or } \\
\text { ITU or surgical/radiological intervention, or } \\
\text { resulting in death }\end{array}$ \\
\hline
\end{tabular}

$E R C P$, endoscopic retrograde cholangio-pancreatography; IHD, ischaemic heart disease. 
Table 8 Complications observed during prospective follow-up

\begin{tabular}{|c|c|c|}
\hline Complication & $\begin{array}{l}\text { Outcome based on all } \\
\text { recorded procedures } \\
\mathrm{n} / \mathrm{N}(\%)\end{array}$ & $\begin{array}{l}\text { Outcome based on } \\
\text { patients' first recorded } \\
\text { procedure } \mathrm{n} / \mathrm{N}(\%)\end{array}$ \\
\hline Post-ERCP pancreatitis & $79 / 5264(1.5)$ & $74 / 4561(1.6)$ \\
\hline \multicolumn{3}{|c|}{ Gastrointestinal haemorrhage } \\
\hline All ERCPs & $46 / 5264(0.9)$ & $40 / 4561(0.9)$ \\
\hline BS procedures & $33 / 2260(1.5)$ & $28 / 2110(1.3)$ \\
\hline Cholangitis & $59 / 5264(1.1)$ & $48 / 4561(1.0)$ \\
\hline Duodenal perforation & $22 / 5264(0.4)$ & $20 / 4561(0.4)$ \\
\hline Miscellaneous & $74 / 5264(1.4)^{*}$ & $54 / 4561(1.2)$ \\
\hline Anyt & $268 / 5264(5.1)$ & $230 / 4561(5.0)$ \\
\hline
\end{tabular}

BS, biliary sphincterotomy; ERCP, endoscopic retrograde cholangiopancreatography.

*Includes 5 cases of basket impaction/mechanical failure of lithotriptor; 1 oesophageal perforation; 2 ductal perforations with 1 case of subcapsular biloma; 13 cases of acute cholecystitis (including 1 case of gallbladder empyema); 1 case of gallstone ileus; 1 episode of haemorrhage arising from a combined percutaneous procedure; 1 Addisonian crisis; 3 complications of antibiotic administration (allergic rash in 1, Clostridium difficile diarrhoea in 1, anaphylaxis in 1); 5 cases of gastrointestinal disturbance (nausea and vomiting/constipation); 24 episodes of abdominal pain which did not meet the diagnostic criteria for pancreatitis; 1 episode of epistaxis temporally related to the procedure; 13 cardiorespiratory complications; 1 neuropsychiatric reaction to medication; 1 case of possible rigors without documented fever; 2 cases of acute renal failure.

tProcedures could result in more than one complication.

varied significantly (table 6). Among 3120 patients undergoing their first ever ERCP, $2242(70 \%)$ underwent the procedure successfully at first attempt. Of the remaining 968 patients, 228 $(24 \%)$ were recorded as undergoing $\geqslant 1$ repeat procedure(s) during the study period, of which 170 (75\%) were successful. The cumulative success rate during the study period for patients with no history of ERCP before the commencement of the study was therefore 2412/3210 (75\%). Further (successful) procedures were performed probably after data collection ceased. Non-endoscopic management of patients in whom ERCP failed was not examined. Overall, completion of all intended imaging and treatment in the course of a single procedure was achieved in 3707 of $5264(70.4 \%)$ ERCPs studied.

\section{Adverse events}

ERCP complications were defined and graded in severity according to the consensus criteria developed by Cotton et al (table 7). An ERCP-related complication followed 268 of 5264 (5.1\%) prospectively studied procedures. Table 8 summarises the events.

Of the 4561 patients who participated, 121 (2.7\%) died within 30 days of their first recorded ERCP (Box 1). This is consistent with previously published data, both from the $\mathrm{UK}^{2}$ and from North America. ${ }^{3}$ Mortality from all causes correlated with ASA score (fig 2). In particular, over $60 \%$ of patients with ASA score 5 died within 30 days of ERCP. Death was largely related to progression of underlying disease, but 21 fatalities arose from an ERCP complication, of which 20 occurred within 30 days of the patients' first recorded procedure (table 9). This represented a procedure-related mortality of $0.4 \%$ (21/5264). In total, 13 of $21(62 \%)$ fatal complications occurred in patients aged $\geqslant 75$ years, and 7 of 21 (33\%) fatal complications in patients with an ASA score of 3-5. This suggested that 1 in 100 (7/670) procedures carried out on a patient with an ASA score of 3-5 resulted in an ERCP-related death.

\section{Patient satisfaction}

Patients were supplied with a (voluntary) questionnaire to be completed I week after the procedure. In total, 2059 of 4561 (45\%) patients completed the questionnaire after their first recorded procedure, at a mean of 11 days after ERCP. The mean age of $\square$ Percentage of patients per ASA score dying within 30 days of first recorded ERCP (121 deaths following 4561 procedures; missing data $=3$ deaths among 166 patients without recorded ASA grade)

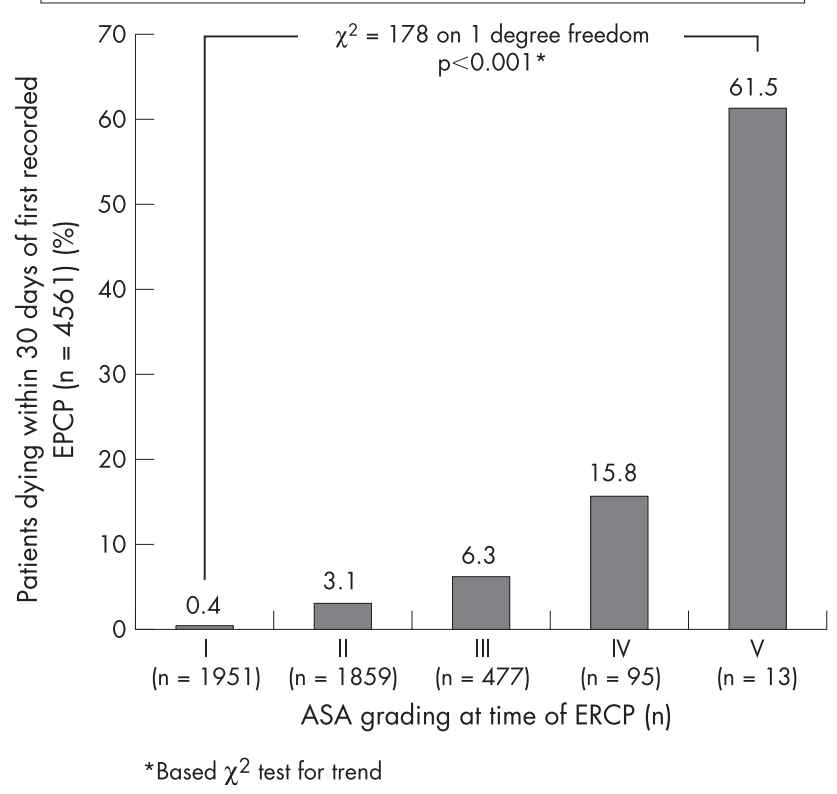

Figure 2 ASA score and mortality from all causes within 30 days of endoscopic retrograde cholangio-pancreatography (ERCP).

respondents was 64.6 years. ASA score was 1-2 in 1829 of 2059 $(89 \%)$ respondents, and 128 of $2059(6 \%)$ respondents had undergone an urgent ERCP. At the time of reply, 1724 of 2059 $(84 \%)$ patients had had the result of their ERCP explained. Most patients ( 1968 of 2059; 96\%) were "fairly" or "very" satisfied with the explanation they had been given, with 1908 of 2059 (93\%) patients reporting the ERCP to be similar or very similar to what they had been led to expect. Patients were not asked to specifically rate their discomfort with the procedure. However, in total, 682 of $2059(33 \%)$ patients made free text comments, and of these 85 ( $12 \%)$ indicated experience of pain or discomfort.

\section{PROCEDURES EXCLUDED FROM ANALYSIS}

Thirteen units were able to provide supplementary data on patients excluded from prospective study. On the basis of this information, age, sex and indication for ERCP did not seem to significantly differ between study participants and nonparticipants (table 10).

Nonetheless, 30-day mortality from all causes was higher among these non-participants. This may have been the result of disease progression among those patients who were too sick to give consent. Assuming that all of the 1646 procedures not entered into the audit (table 2) represented a patient's first recorded ERCP, the extrapolated mortality in this group would amount to $18 / 320^{*} 1646=92$. Combined with the 121 of 4561 deaths observed among participants following their first recorded procedure, this suggested 30-day mortality for all patients was approximately $3.4 \%$.

\section{DISCUSSION}

The latest BSG audit is one of the largest and most comprehensive surveys of ERCP practice ever undertaken. Over $80 \%$ of eligible endoscopists participated, and 30-day follow-up was achieved for over $90 \%$ of the ERCPs recorded. These represent the major strengths of the dataset. The 
Box 1: Deaths occurring within 30 days of first recorded endoscopic retrograde cholangiopancreatography $(n=121)$

Cause of death related to $\operatorname{ERCP}(n=20)^{*}$

- Cholangitis; $n=4$

- $\mathrm{Gl}$ bleeding and cholangitis; $\mathrm{n}=2$

- Gl bleed alone; $n=2$

- Duodenal perforation; $n=3$

- Oesophageal perforation; $n=1$

- Pancreatitis; $n=1$

- Equipment failure (broken emergency lithotripter); $n=1$

- Cardiorespiratory; $\mathrm{n}=4$

- Acute renal failure; $n=2$

Cause of death unrelated to ERCP $(n=101)$

- Progression of primary pancreatobiliary malignancy; $n=55$

- Pre-existing biliary sepsis including cholecystitis; $n=4$

- Pre-existing pancreatitis; $n=3$

- Chronic liver disease; $n=2$ (PSC, idiopathic cirrhosis)

- Malignancy; non pancreatobiliary primary, or unspecified; $n=27$

- Cardiopulmonary disease; $n=5$

- Death in community; $\mathrm{n}=5 \dagger$

$E R C P$, endoscopic retrograde cholangio-pancreatography; $\mathrm{Gl}$, gastrointestinal. "Twenty ERCP-related deaths occurred within 30 days of the patient's first recorded procedures. One further case of fatal ERCP cholangitis occurred within 30 days of a second ERCP, but $>30$ days after the patient's first recorded procedure. Two patients who experienced post-ERCP GI bleeding also met the definition for post-ERCP cholangitis. A trapped lithotripter basket occurred in a patient with ischaemic heart disease who died of multi-organ failure following emergency surgical exploration.

tCause of death could not be verified for five cases. All such deaths occurred in the community, at a mean of 15 days after the procedure, and cases were analysed as unrelated to the procedure. requirement for patients to consent to data transfer, which resulted in a minority of consecutive ERCPs being excluded from the analysis, is recognised as a limitation. Nonetheless, findings are still considered to be representative of UK practice.

For professional bodies, the data clarify a number of training and manpower issues. In particular, the estimated national workload of 48000 ERCPs/annum is comparable to that reported by a previous BSG survey conducted in 1998. ${ }^{14}$ ERCP therefore contrasts with other endoscopic interventions in that there is no evidence of increasing demand. Indeed, as a diagnostic test, its role may further diminish as access to competing technologies such as magnetic resonance and endoscopic ultrasound widens. The finding that 81 of 236 (34\%) UK acute hospitals were engaged in training 91 specialist registrars suggests that there were approximately 270 ERCP trainees nationally. It should be noted that during 2004 the total number of gastroenterology registrars in the UK equalled 550 (http://www.tig.org.uk/manpower.htm). These figures are of concern, given that only 11 of the 57 consultant gastroenterology posts advertised in England during the same period indicated that ERCP skills were required or desirable.

The problem of large numbers of ERCP trainees performing relatively few procedures is not unique to the UK..$^{15}$ As yet, there is no international consensus regarding the minimum standards for ERCP training and accreditation. The American Society for Gastrointestinal Endoscopy ${ }^{12}$ has suggested an $80 \%$ success rate in cannulation/basic treatment as a benchmark for competence. Although recognising that trainees with an experience of $<180$ 200 ERCPs are unlikely to be competent, it avoids recommending a mandatory minimum number of procedures to be performed as part of training. This contrasts with the guidelines of the Australian Conjoint Committee for Recognition of Training in Gastrointestinal Endoscopy, which requires that a trainee perform 200 ERCPs independently in order for his or her training to be recognised (http://conjoint.gesa.org.au/applicantinformation/ procedural.cfm). European practice varies, although the Gastroenterology Section of the Union of European Medical Specialists has suggested that trainees in ERCP should have participated in at least 150 procedures (http://www.gastrohep.com/EUMS/UEMSI.pdf). In the UK, the Joint Advisory Group on Gastrointestinal Endoscopy has indicated that trainees should aspire for a cannulation rate of $90 \%$ and show an ability to perform basic treatment independently, but does not stipulate a mandatory success rate or specific number of procedures to be completed before appointment as a specialist.

Table 9 Patient characteristics, participants and non-participants

\begin{tabular}{lll}
\hline Characteristics & Participants & Non-participants* \\
\hline Mean (SD) age of patient (years) & $65.0(16.7)$ & $66.9(17.3)$ \\
Number of female patients & $2591 / 4561(57 \%)$ & $193 / 320(60 \%)$ \\
30-day mortality (following first recorded & $121 / 4561(2.7 \%)$ & $18 / 320(5.6 \%)$ \\
procedure) & & \\
Suspected diagnosis before the (first recorded) & & \\
procedure: & & $112 / 209(54 \%)$ \\
Ductal stones $\dagger$ & $2477 / 4561(54 \%)$ & $50 / 209(24 \%) \neq$ \\
Malignancy & $891 / 4561(20 \%)$ & $20 / 209(9 \%)$ \\
Pancreatitis (acute and chronic) & $435 / 4561(10 \%)$ & $8 / 209(4 \%)$ \\
Cholangitis & $245 / 4561(5 \%)$ & $10 / 209(5 \%)$ \\
Biliary leak & $100 / 4561(2 \%)$ & $3 / 209(1 \%)$ \\
Sphincter of Oddi dysfunction & $69 / 4561(1 \%)$ & $6 / 209(3 \%)$ \\
Other diagnosis & $213 / 4561(5 \%)$ & - \\
Not specified & $131 / 4561(3 \%)$ & \\
\hline
\end{tabular}

Values are given as $\mathrm{n} / \mathrm{N}(\%)$.

*As part of an exit questionnaire, 13 units supplied anonymised information on age and sex for those patients $(n=320)$ excluded from analysis, with 30 -day mortality derived from the national register of deaths. Supplementary data regarding indication were available from 9 units for 209 patients.

tWithout coexisting pancreatitis or cholangitis.

flncludes 25 patients with indication listed as jaundice with dilated duct, but with no evidence of stones. 
How best is it then to proceed? The authors argue that the quality of ERCP services is affected as a consequence of there being too many trainees, who are unable to gain adequate experience, given the current volume of work in many ERCP centres. As such there is a requirement for a smaller number of "ERCPists", who would receive more intensive schooling in therapeutic techniques. This approach would help address the variation observed in individual practice. It would also be appropriate, given that low annual workload may be associated with an increased incidence of adverse events. ${ }^{3416}$ To be successful, this requires a change in several aspects of ERCP training. In particular, training would need to be organised at a regional rather than an institutional level. To achieve this, the authors suggest formal ERCP training schemes. Under such arrangements, training lists in ERCP would be assigned to a minority of trainees by a single clinician who would be responsible for co-ordinating ERCP training within their region. Ideally, such schemes would incorporate all specialties with an interest in biliary endoscopy. The exact model by which training would be delivered might be expected to vary. Some programmes may opt to provide trainees with $\geqslant 2$ lists per week, undertaken at different sites within their region. Others may provide "ERCP fellowships" within a single institution, as part of a centralised ERCP service. Regular hepatobiliary multidisciplinary team meetings would be expected at all units engaged in training. There would also be a need for facilities to be in place for ongoing clinical audit, and trainers would have to be able to demonstrate competence in cannulation and basic treatment. In all schemes, trainees would be expected to participate in a minimum number of procedures in the last 2 years of specialist training (which would perhaps be about 300 ERCPs, and certainly not less than 200). Trainees would need to be competent in basic upper gastrointestinal endoscopy before commencing ERCP training, and entry into the scheme would be considered in light of endoscopy trainers' reports and future career intentions. Only those with a firm intention to provide ERCP services after the completion of specialist training would be considered for enrolment into the scheme, although a short "orientation" course may be appropriate to allow undecided trainees to be exposed to the procedure.

Variations seen in practice also have implications for individual units, irrespective of whether or not they train endoscopists. In particular, they underline the need to ensure that appropriate guidelines, tailored where necessary to local circumstance, are implemented. It is disappointing that some units have no dedicated recovery area for ERCP patients and that access to alternative forms of imaging (magnetic resonance or endoscopic ultrasound) is not yet universal. Adequate resources in these areas are essential.

Despite the above concerns, several positive points emerge from the study, and individual endoscopists can be reassured by findings in a number of key areas. Firstly, the vast majority of patients undergoing ERCP have evidence of structural disease on pre-ERCP imaging, and 9 out of 10 patients are scheduled with therapeutic intent. Moreover, patients at high surgical risk (ASA score $\geqslant 3$ ) represent only a small fraction of patients undergoing the procedure. These data confirm that appropriate patient selection is the norm, and contrast with the inference drawn by a recent NCEPOD report ${ }^{2}$ that potentially large numbers of inappropriate procedures are being performed on "high-risk" patients.

In addition, the current study does not support the supposition that large numbers of patients undergo ERCP without appropriate checks on parameters such as blood clotting. Results of the satisfaction questionnaire, although based on a self-selected sample, suggest that most patients are appropriately counselled before endoscopy.

Of equal importance, the rates of complication and mortality observed compare favourably to those of other large prospective studies performed in Europe and the US,,$^{3-6}{ }^{17}$ and are slightly lower than those previously reported in the UK. ${ }^{18}$ The relatively low pancreatitis rates almost certainly reflect endoscopists' avoidance of ERCP in patients with a low probability of structural disease (including those with suspected Sphincter of Oddi Dysfunction), as it is this group that has been consistently found to experience high morbidity from ERCP. ${ }^{3-5}{ }^{19}$ It should also be noted that the number of reported cases are in part determined by applying the definition of mild pancreatitis, which required not only documented hyperamylasaemia of at least three times the upper limit of normal, but also a delay in discharge following ERCP of at least two nights. Where investigators count admissions of one night or set lower thresholds of hyperamylasaemia, reported rates of mild pancreatitis can be expected to be significantly higher.

The study does confirm that high ASA score is associated with mortality, and that sepsis is an under-recognised cause of morbidity and mortality after ERCP. For patients with ASA scores of 4 and 5, early involvement of an anaesthetist and personal review by the endoscopist performing the procedure (as per NCEPOD guidelines) would therefore seem sensible. In addition, endoscopists need to disclose the risk of sepsis to patients when seeking consent, and ensure that measures are in place to ensure that postERCP cholangitis is promptly identified and treated.

Finally, a number of central questions remain for ERCP endoscopists, both in the UK and elsewhere. Firstly, the factors that are associated with competence, and in particular the minimum "safe" workloads for a unit or endoscopist, remain elusive and require further investigation. Although a relationship between numbers of procedures and outcome is intuitive, it has not emerged in studies to date as a strong independent predictor. However, the implications of a low workload on the cannulation rates achieved by trainees seem to be clear. Consequently, overall success rates would be best improved by concentration of greater numbers of ERCPs in a smaller number of centres, with greater restriction on who trains (and retrains!). Related to this question is how one should compare the performance between individuals and units with differing case-mix. Although a number of scores have been proposed, ${ }^{20}{ }^{21}$ validation in a large-scale prospective study is awaited. Also of interest are the key risk factors for complication and death after ERCP, and in particular whether risk factors can be incorporated into predictive models. It is hoped that further analysis of the BSG dataset will help raise some of these important queries.

\section{ACKNOWLEDGEMENTS}

The BSG sincerely thank all those members of staff who assisted in data collection and local co-ordination of the project. The following units contributed to prospective data collection (the number of procedures are given in brackets).

Royal Liverpool University Hospital (292); Guy's and St Thomas' Hospital NHS trust (249); Russell's Hall Hospital, Dudley (235); Queen's Medical Centre, Nottingham (232); Chelsea and Westminster Hospital, London (216); Wythenshawe Hospital, Manchester (186); Walsgrave Hospital, Coventry (152), Basildon Hospital (147); Stepping Hill Hospital, Stockport (145); University Hospitals Birmingham (137); Darent Valley Hospital, Dartford (127); Queen Elizabeth II Hospital, Welwyn Garden City (126); St Mary's Hospital, London (109); The Middlesex Hospital, London (105); Birmingham Heartlands Hospital (103); Royal Free Hospital, London (100); Arrowe Park Hospital, Upton (99); Princess Royal University Hospital, Orpington (97); Doncaster Royal Infirmary (93); Northwick Park and St Mark's Hospital, London (93); William Harvey Hospital, Ashford (92); Royal Hallamshire Hospital, Sheffield (86); King George Hospital, Goodmayes (83); Queen Elizabeth Hospital, Woolwich (82); Royal Wolverhampton Hospitals (81); Royal London Hospital (79); Royal Sussex County Hospital, Brighton (77); Burnley General Hospital (77); Chesterfield Royal Infirmary (74); Broomfield Hospital, Chelmsford (74); Hemel Hempstead Hospital (73); Royal Oldham Hospital (71); Manchester Royal Infirmary (65); Conquest Hospital, St Leonards-on-Sea (62); 
Warwick Hospital (59); Princess Royal Hospital, Telford (57); Hope Hospital, Salford (57); Tameside General Hospital, Ashton Under Lyne (55); Whiston Hospital, Prescot (54); Lewisham Hospital, London (54); Colchester General Hospital (54); Sandwell Hospital, West Midlands (52); Queen Elizabeth Queen Mother Hospital, Margate (52); Fairfield General Hospital, Bury (50); Worcestershire Royal Infirmary (49); Royal Shrewsbury Hospital (48); Chorley District General (44); Leicester Royal Infirmary (41); West Middlesex Hospital, Isleworth (39); Derby City Hospital (38); Royal Bolton Hospital (37); Maccelsfield General Hospital (36): George Eliot Hospital, Nuneaton (31); The County Hospital Hereford (30); Kent and Canterbury Hospital, Canterbury (26); Leicester General Hospital (26); Maidstone Hospital (24); Southport District General Hospital (24); Blackburn Royal Infirmary (21); Glenfield General Hospital, Leicester (17); North Manchester General Hospital, Crumpsall (16); Eastbourne District General Hospital (15); University Hospital Aintree, Liverpool (12); Northern General Hospital, Sheffield (11); Nottingham City Hospital (10); Charing Cross and Hammersmith Hospital, London (6).

\section{Authors' affiliations}

Earl J Williams, Martin Lombard, Department of Gastroenterology, Royal Liverpool University Hospital, Liverpool, UK

Steve Taylor, Paula J Williamson, Centre for Medical Statistics and Health Evaluation, School of Health Sciences, University of Liverpool, Liverpool, UK Peter Fairclough, Department of Gastroenterology, Barts and The London NHS Trust, London, UK

Adrian Hamlyn, Department of Gastroenterology, Russell's Hall Hospital, Dudley, West Midlands, UK

Richard F Logan, Division of Epidemiology and Public Health, Queen's Medical Centre, Nottingham, UK

Derrick Martin' ', Department of Radiology, Wythenshawe Hospital, Manchester, UK

Stuart A Riley, Department of Gastroenterology, Northern General Hospital, Sheffield, UK

Peter Veitch ${ }^{2}$, Department of Surgery, Royal Free Hospital, London, UK Mark Wilkinson, Department of Gastroenterology, Guy's \& St Thomas' NHS Foundation Trust, London, UK

${ }^{1}$ Represented the Royal College of Radiologists, UK

${ }^{2}$ Represented the Association of Upper G1 Surgeons, UK

Funding: This project was sponsored and funded by the British Society of Gastroenterology.

Competing interests: None.

Ethical approval: This project was approved by the West Midlands MREC on 4 August 2003: reference number MREC 03/7/051.

\section{REFERENCES}

1 Freeman ML, Adverse outcomes of ERCP. Gastrointest Endosc 2002;56(Suppl):S273-82.

2 NCEPOD. Scoping our practice; The 2004 Report of the National Confidential Enquiry into Patient Outcome and Death. London: NCEPOD, 2004, http:// www.ncepod.org.uk/2004.htm (accessed 28 Mar 2007).

3 Freeman ML, Nelson DB, Sherman S, et al. Complications of endoscopic biliary sphincterotomy. N Engl J Med 1996;335:909-18.

4 Loperfido S, Angelini G, Benedetti G, et al. Major early complications from diagnostic and therapeutic ERCP: a prospective multicenter study. Gastrointest Endosc 1998:48:1-10.

5 Freeman ML, DiSario JA, Nelson DB, et al. Risk factors for post-ERCP pancreatitis: a prospective, multicenter study. Gastrointest Endosc 2001;54:425-34

6 Masci E, Toti G, Mariani A, et al. Complications of diagnostic and therapeutic ERCP: a prospective multicenter study. Am J Gastroenterol 2001;96:417-23.

7 Joint Advisory Group on Gastrointestinal Endoscopy. Guidelines on the training, appraisal and assessment of trainees in Gl endoscopy, London; JAG, 2004.http://www.thejag.org.uk/JAG_2004.pdf (accessed 28 Mar 2007).

8 Jowell PS, Baillie J, Branch MS, et al. A prospective study of training in endoscopic retrograde cholangiopancreatography. Ann Intern Med 1996; 125:983-9.

9 British Society of Gastroenterology. Guidelines for informed consent for endoscopic procedures. London: BSG, 1999, http://www.bsg.org.uk (accessed 28 Mar 2007).

10 British Society of Gastroenterology. Safety and sedation during endoscopic procedures, London: BSG, 2003. http://www.bsg.org.uk (accessed 28 Mar 2006).

11 Implementing and ensuring safe sedation practice for healthcare procedures in adults. Report of a Working Party established by the Royal College of Anaesthetists, London 2001

12 ASGE. Principles of training in gastrointestinal endoscopy. From the American Society for Gastrointestinal Endoscopy. Gastrointest Endosc 1999;49:845-53.

13 Cotton PB, Lehman G, Vennes J, et al. endoscopic sphincterotomy complications and their management: an attempt at consensus. Gastrointest Endosc 1991;37:383-93.

14 Allison MC, Ramanaden DN, Fouweather MG. Provision of ERCP services and training in the United Kingdom. Endoscopy 2000;32:693-9.

15 Kowalski T, Kanchana T, Pungpapong S. Perceptions of gastroenterology fellows regarding ERCP competency and training. Gastrointest Endosc 2003;58:345-9.

16 Rabenstein T, Schneider HT, Nicklas M, et al. Impact of skill and experience of the endoscopist on the outcome of endoscopic sphincterotomy techniques. Gastrointest Endosc 1999;50:628-36.

17 Christensen M, Matzen P, Schulze S. Complications of ERCP: a prospective study. Gastrointest Endosc 2004;60:721-31.

18 Tanner AR, ERCP: present practice in a single region. Suggested standards for monitoring performance. Eur J Gastroenterol Hepatol 1996;8:145-8.

19 Mehta SN, Pavone E, Barkun JS. Predictors of post-ERCP complications in patients with suspected choledocholithiasis. Endoscopy 1998;30:457-63.

20 Schutz SM, Abbott RM. Grading ERCPs by degree of difficulty: a new concept to produce more meaningful outcome data. Gastrointest Endosc 2000;51:535-9.

21 Ragunath K, Thomas LA, Cheung WY. Objective evaluation of ERCP procedures: a simple grading scale for evaluating technical difficulty. Postgrad Med J 2003:79:467-70.

\title{
EDITOR'S QUIZ: GI SNAPSHOT
}

\begin{abstract}
Answer
From the question on page 820

The endoscopic image revealed a volcano-like mass lesion with hyperaemia, and swollen mucosa over the lower part of the body of the stomach, with some stool-like fluid observed (fig 1). CT scan disclosed a fistula between the stomach and the transverse colon (fig 2). A clinical diagnosis of gastrocolic fistula due to colonic cancer with liver metastasis was made. The diagnosis was confirmed at surgery for mechanical ileus after 2 weeks. Pathological examination of the resected tumour revealed adenocarcinoma arising in the colonic mucosa with infiltration into the gastric submucosa.

Advanced neoplasm is the most common aetiology of gastrocolic fistula. Other causes, including benign gastric ulcer, Crohn's disease, cytomegalovirus-related gastritis and percutaneous endoscopic gastrostomy, have been reported in the literature. Common symptoms include diarrhoea, weight loss, feculent vomiting, epigastralgia and fatigue. The diagnosis is usually made on barium contrast radiography, endoscopy or CT. For a benign aetiology, treatment usually includes parenteral nutrition and intravenous H2-receptor antagonists or proton pump inhibitors. Radical en-bloc surgery with adjuvant chemotherapy is usually required to provide long-term survival for patients with malignancy.
\end{abstract}

